EXTENDED REPORT

\title{
Sequential changes of parathyroid hormone related protein (PTHrP) in articular cartilage during progression of inflammatory and degenerative arthritis
}

\author{
E Gómez-Barrena, O Sánchez-Pernaute, R Largo, E Calvo, P Esbrit, G Herrero-Beaumont
}

Ann Rheum Dis 2004;63:917-922. doi: 10.1136/ard.2003.008904

See end of article for authors' affiliations

Correspondence to:

Professor E Gómez-

Barrena, Servicio de

Cirugía Ortopédica y

Traumatología, Fundación

Jiménez Díaz, Avda. Reyes

Católicos 2, E-28040

Madrid, Spain;

egomez@fjd.es

Accepted 8 October 2003

\begin{abstract}
Objective: To investigate immunolocalisation of parathyroid hormone related protein (PTHrP) in two sequential models of experimental cartilage damage (inflammatory and degenerative) in order to elucidate differences in chondrocyte response to the disease.

Methods: Immunohistochemistry with a polyclonal rabbit antiserum to the N-terminal domain of PTHrP was used to detect this protein in two different rabbit models sharing progressive cartilage damage: antigen induced arthritis (AIA) and osteoarthritis $(\mathrm{OA})$ secondary to partial medial meniscectomy. Cartilage specimens from early ( 2 days in AIA; 8 weeks in experimental OA) and late ( 3 weeks in AIA; 52 weeks in OA) disease were compared.

Results: Cell and matrix PTHrP staining in early AIA and OA was similar to that in controls. Late AIA cartilage showed a significant decrease in PTHrP positive cells and in the cartilage matrix. In contrast, at late OA stages, distinct PTHrP positivity was detected in proliferating cell clones, as assessed by proliferating cell nuclear antigen staining around cartilage damaged areas.

Conclusion: PTHrP staining of hyaline articular cartilage shows a different pattern during progression of each type of arthritis: an overall decrease associated with the inflammatory disease, and an increase in the proliferating chondrocyte clones with degenerative arthritis.
\end{abstract}

$P$ arathyroid hormone $(\mathrm{PTH})$ related protein $(\mathrm{PTHrP})$ is a ubiquitous protein produced by most tissues in the body. $^{12}$ It promotes chondrocyte proliferation and inhibits terminal differentiation and apoptosis in both perichondral and endochondral cells. ${ }^{2}$ PTHrP gene ablation in mice leads to an increased differentiation of chondrocytes in the growth plate. ${ }^{4}$ However, PTHrP fails to induce chondrocyte hypertrophy in bovine articular cartilage in culture. ${ }^{5}$ It appears that PTHrP participates in a negative feedback loop involving the production of Indian hedgehog protein to modulate chondrocyte differentiation. ${ }^{6}$ The $\mathrm{N}-$ terminal region of both PTH and PTHrP binds to the PTH/ PTHrP type 1 receptor, leading to activation of adenylate cyclase and phospholipase C/protein kinase C. ${ }^{78}$ In addition, the ligand-receptor complex can be internalised into the nucleus, at least in bone cells. ${ }^{9}$

PTHrP is induced as part of the cytokine network in rheumatoid arthritis (RA) synovial membrane and in osteoarthritis (OA) cartilage. ${ }^{30-13}$ In human, end stage OA, where more subchondral calcification is apparent, increased PTHrP staining has been reported. ${ }^{11}$ This cannot be easily reconciled with a putative effect of PTHrP to limit the subchondral calcification front during progression of OA. ${ }^{2}$ To clarify this issue further, we performed an immunohistochemical study to detect PTHrP in two well established experimental models for inflammatory and degenerative arthritis-namely, antigen induced arthritis (AIA) and postmeniscectomy OA. ${ }^{14-16}$ In contrast with previous studies in human cartilage, these models allowed us to evaluate early versus late changes in PTHrP staining.

\section{MATERIALS AND METHODS}

Animal models

Following ethical guidelines for animal research studies, an experimental protocol was developed that complied both with specific European Union regulations and the NIH guide for the care and use of laboratory animals. The protocol was accepted by the animal studies committee in our institution. A total of 32 white New Zealand male rabbits ( 8 weeks old, $2.5-3.5 \mathrm{~kg}$ ) were obtained from B\&K Universal (Madrid, Spain).

For induction of AIA, ovalbumin was injected into the knee of 16 rabbits after preliminary subcutaneous injection, as published elsewhere. ${ }^{14}{ }^{15}$ Seven animals were killed by intracardiac administration of sodium pentobarbital (50 mg/kg) (Pentothal, Abbott, Madrid, Spain) at day 2 (earlier stage of AIA), and nine animals at week 3 (later stage of AIA).

Nine rabbits underwent left partial medial meniscectomy to induce degenerative knee lesions, as described previously. ${ }^{16}$ Operations were performed under general anaesthesia with intramuscular xylazine (Rompun, Bayer, Spain), $2 \mathrm{ml} / \mathrm{kg}$, and ketamine (Ketolar, Parke-Davis, Spain) HCl, 5:1, under sterile conditions, and perioperative antibiotic and analgesic coverage. All the animals were permitted free cage activity after surgery. Five animals were killed as described at 8 weeks to obtain joints with early OA, and four at 52 weeks to obtain joints at later OA stages.

A group of six control knees was formed, with two normal knees from animals without contralateral injury and four contralateral knees from meniscectomised animals killed at 8 weeks. This was done for ethical reasons, to minimise the deaths of normal animals. All variables in normal and contralateral control knees were compared and no significant differences were detected, thus confirming their inclusion as controls. In contrast, contralateral knees from meniscectomised animals killed at 52 weeks showed significant

Abbreviations: $\mathrm{AIA}$, antigen induced arthritis; $\mathrm{BSA}$, bovine serum albumin; OA, osteoarthritis; PBS, phosphate buffered saline; PCNA, proliferating cell nuclear antigen; PTH, parathyroid hormone; PTHrP, parathyroid hormone related protein; RA, rheumatoid arthritis 
differences in Mankin score and cell density in the surface, suggesting changes due to age and/or disease, and were excluded from the control group. Additionally, five normal knees from animals used in unrelated experiments underwent a sham operation for meniscectomy, consisting of knee arthrotomy.

The meniscectomised, normal, and sham knees were examined for gross pathological changes. Cartilage slices were prepared from the medial femoral condyle and medial tibial plateau from all the animals. Each specimen was fixed in $4 \% p$-formaldehyde in phosphate buffered saline (PBS) for 12 hours. After demineralisation with EDTA at $4^{\circ} \mathrm{C}$, paraffin sections were prepared by standard histological procedures. The Mankin score ${ }^{17}$ was calculated from these sections by an experienced researcher who did not know either the case or the evolution time.

\section{PTHrP immunohistochemistry}

Immunohistochemistry was performed on $5 \mu \mathrm{m}$ thick sections with the avidin-biotin-peroxidase complex method, as described previously. ${ }^{18}$ Immunolocalisation of PTHrP was performed with the polyclonal rabbit antihuman PTHrP antiserum C13, recognising the 24-35 epitope in the human PTHrP molecule. ${ }^{19}$ Briefly, the slides, once deparaffinised and rehydrated, were immersed in $3 \% \mathrm{H}_{2} \mathrm{O}_{2}$ for 30 minutes to block endogenous peroxidase. Subsequently, a 30 minute incubation in $40 \mathrm{mU} / \mathrm{ml}$ chondroitinase in PBS was performed, followed by a 30 minute incubation in $6 \%$ normal swine serum $/ 4 \%$ bovine serum albumin) in PBS (blocking solution) to minimise non-specific staining. The sections were treated with antiserum $\mathrm{C13}$, at 1:400 dilution in blocking solution overnight at $4^{\circ} \mathrm{C}$, or with non-immunogenic rabbit IgG as negative staining controls. After washing with PBS, sections were incubated with biotinylated swine antirabbit IgG (Dako, Glostrup, Denmark), at 200-fold dilution, for 30 minutes, followed by incubation with avidin-biotin-peroxidase complex (Dako) and 3,3'-diaminobenzidine (Sigma, St Louis, MO, USA) as the chromogen. Tissue sections were counterstained with Mayer's haematoxylin (Sigma). As negative controls, the primary antiserum was replaced by PBS, or it was preincubated overnight with an excess of $\left[\mathrm{Cys}^{23}\right]$ human PTHrP (24-35) amide, the immunogen used to raise this antibody. ${ }^{18}$

Cartilage sections were evaluated for matrix and cellular PTHrP. The cartilage of the superficial, middle, and deep layers was graded as follows: 3 (very intense), 2 (intense), 1 (weak), and 0 (none). Cellular positivity was graded with a five point score: 0 (negative), $1 \quad(<1 \%$ positive cells), 2 (1-25\% positive cells), 3 (25-50\% positive cells), and 4 $(>50 \%$ positive cells). Cell density changes were recorded using a four point score: 0 (none), 1 (scarce), 2 (spread), and 3 (abundant). Staining related to cartilage clefts was also recorded when seen. To avoid bias, evaluation was performed by three investigators who did not know the case and the experiment, and a consensus was reached about the semiquantitative score in every section. Microphotographs were obtained on a microscope Nikon Eclipse E400 using a Nikon FDX-35 digital camera (Tokyo, Japan).

\section{Proliferating cell nuclear antigen (PCNA) immunostaining}

PCNA immunostaining was carried out using a monoclonal antibody (Dako) at 1:80 dilution in BSA-PBS with 3\% goat serum. Cartilage tissue was previously digested with $40 \mathrm{U}$ avidin-biotin-peroxidase complex chondroitinase for 1 hour at room temperature. Alkaline phosphatase labelled goat anti-Fc mouse IgG (Roche, Germany) was used as secondary antibody, and fast red (Dako) was the chromogen. The tissue samples were then mounted on aqueous medium (Aquatex; Merck, Germany).

\section{Statistical analysis}

Semiquantitative data of joint degeneration evaluated with the Mankin score were displayed as median and rank for each cohort. Semiquantitative immunostaining data in cells and cartilage matrix were analysed as crude variables from experimental AIA and OA cases, and compared with controls. Early and late cases were compared with controls. In addition, AIA specimens were compared with OA specimens. The Mann-Whitney test was used to compare groups of diseased and control specimens, and the Wilcoxon test to compare early and late stages of the corresponding disease.

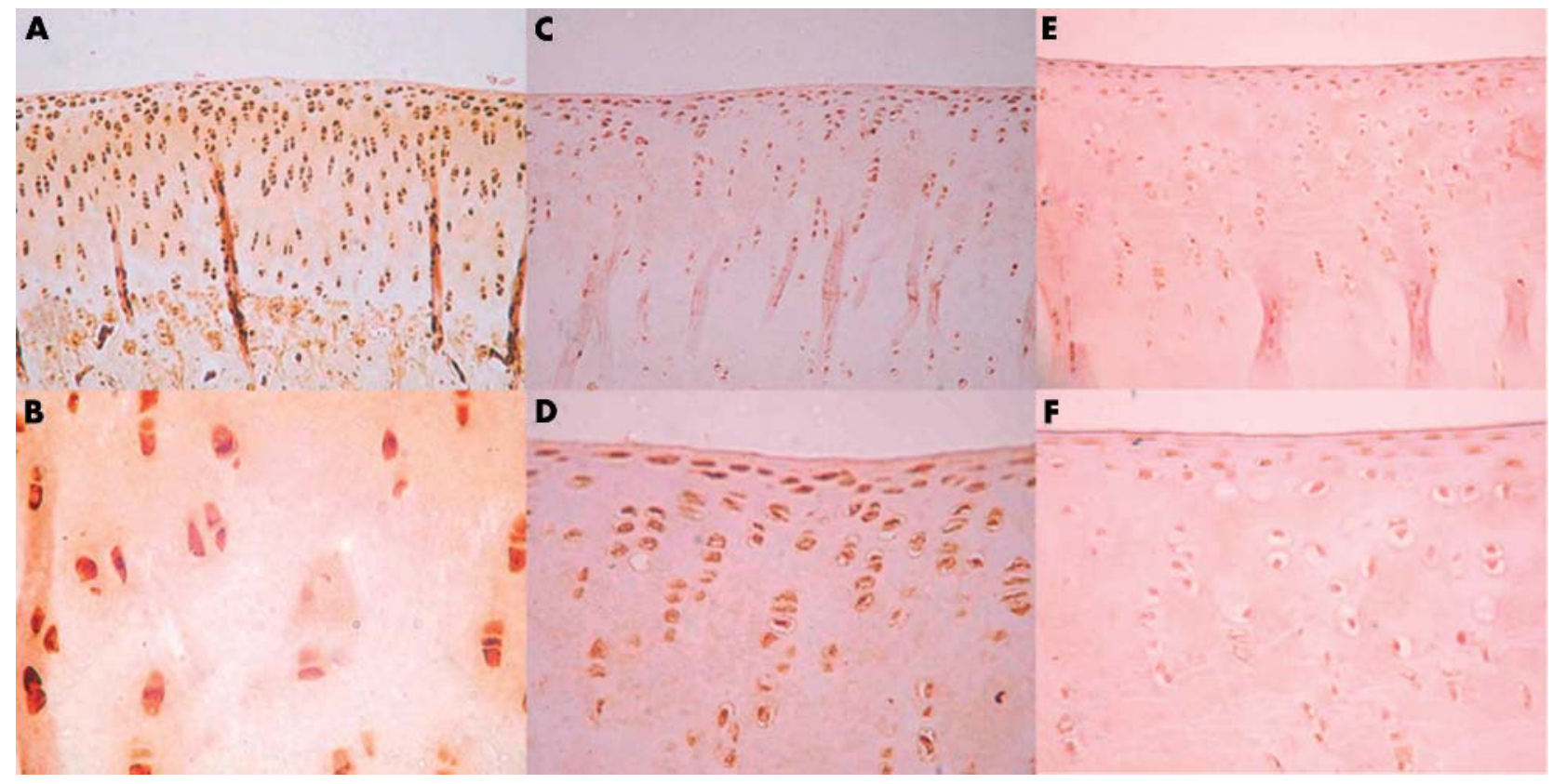

Figure 1 PTHrP immunostaining with anti-PTHrP antiserum $\mathrm{Cl} 3$ in representative sections of medial femoral condyle from either a normal rabbit $(A, B)$, or rabbits with early OA $(C, D)$ or AIA cartilage $(E, F)$. Original magnifications: $\times 100(A, C, E) ; \times 400(B) ; \times 200(D, F)$. 


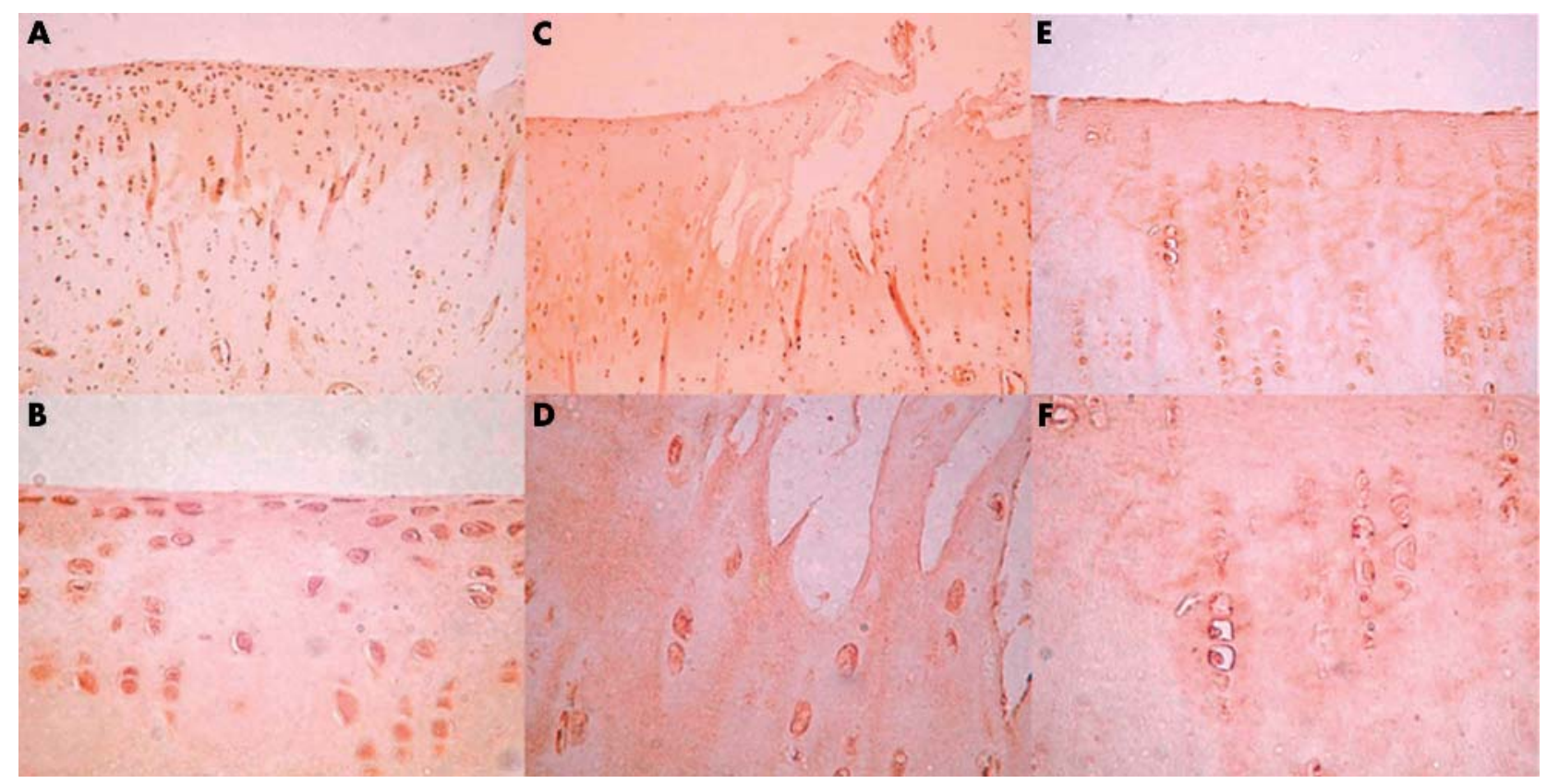

Figure 2 PTHrP immunostaining with antiserum $\mathrm{C} 13$ in representative sections of medial femoral condyle from a normal rabbit (A, B), or rabbits with either late OA (C, D) or AIA cartilage (E, F). A decrease in both cell and matrix PTHrP staining, as well as in cell number, was observed in late AIA samples mostly at the superficial (A,C, E), but also at the deep layer (B, D, F) of cartilage. Of note, cell PTHrP positivity in late OA and AIA. Original magnifications: $\times 100(A, C) ; \times 200(E) ; \times 400(B, D, F)$.

Spearman correlation coefficients were obtained to assess the relationship between PTHrP staining values in cells and matrix, and with the Mankin score and cell density. A value of $\mathrm{p}<0.05$ was considered significant. Statistical analysis was performed with SPSS software (version 9.0; Chicago, IL, USA).

\section{RESULTS}

\section{Histology}

Cartilage in the AIA model showed mild changes at the early (2 days) arthritic stage (median Mankin score 1, rank 0-4; median score for controls was 0). At late (3 weeks) AIA, severe cartilage degradation had occurred, with a significant increase in the Mankin score (median score 3, rank 1-9, $p=0.001)$, and a significant cell density decrease $(p=0.006)$ compared with controls.

In the partial meniscectomy (OA) samples at earlier stages (8 weeks), mild macroscopic degenerative changes were seen, without osteophytes or cartilaginous defects. At later stages (52 weeks), severe joint degeneration was macroscopically evident in all the animals. Eburnated bone appeared after most cartilage was severely thinned and ulcerated in the medial compartment of the knee, while marked osteophytes appeared in both medial and lateral compartments. The Mankin score confirmed the success of the experimental model in achieving joint degeneration after partial medial meniscectomy compared with controls $(p=0.003)$. A significant increase $(p=0.040)$ in the Mankin score was detected in late OA (median Mankin score 8.5 , rank 6-11) compared with early stages (8 weeks, median Mankin score 4, rank 0-6). No significant changes were seen in cartilage samples between normal and sham operated knees. Cell density decreased in OA $(p=0.002)$ compared with controls.

\section{PTHrP detection in experimental AIA}

Cartilage PTHrP positivity in early AIA was similar to that in controls (fig 1) except at the surface, where a significant decrease was detected in cell positivity $(p=0.014)$. Late AIA cartilage showed decreased PTHrP staining (fig 2) in surface cells $(p=0.002)$, mid-zone cells $(p=0.001)$, deep cells $(\mathrm{p}=0.014)$, and in surface matrix $(\mathrm{p}=0.035)$ and deep

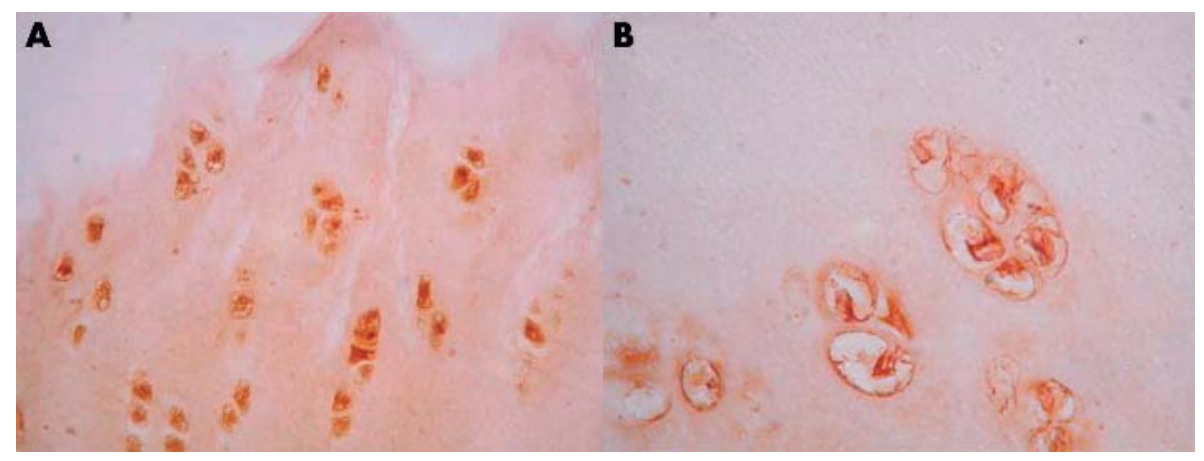

Figure $3 \mathrm{PTHrP}$ immunostaining using antiserum $\mathrm{C} 13$ in representative sections of medial femoral condyle from $\mathrm{OA}$ rabbit cartilage, showing an intense staining in the proliferating cell clones. Original magnifications: $\times 400(A) ; \times 1000(B)$. 


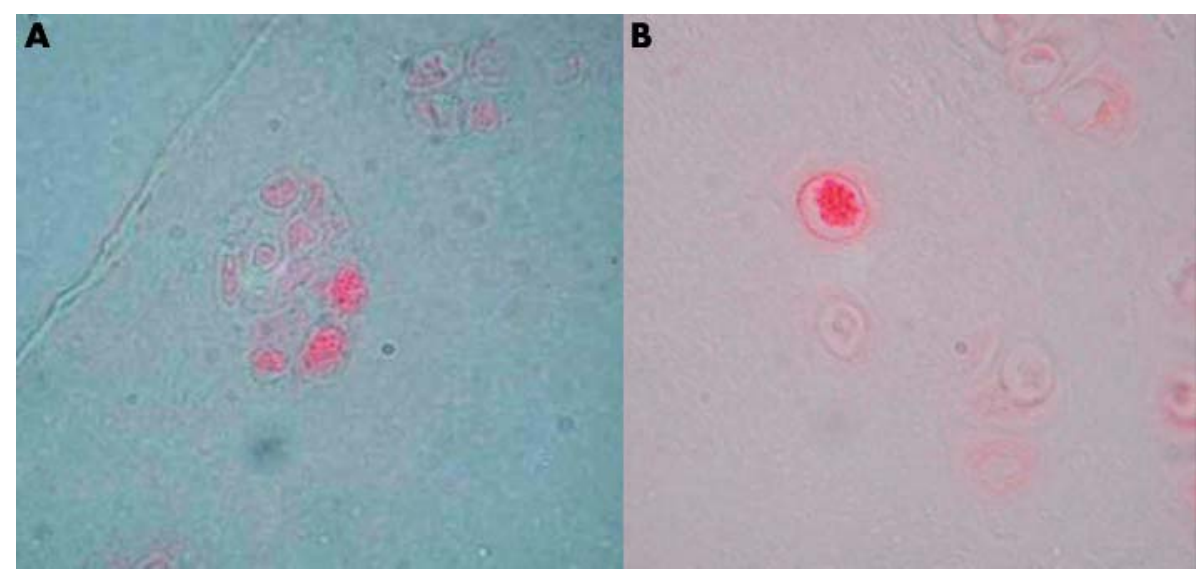

Figure 4 PCNA cell staining in clones around cartilage degenerative lesions (A). Detailed PCNA positive cell (B). Original magnifications: $\times 400(A)$; $\times 1000$ (B).

matrix $(p=0.006)$, compared with that in controls (fig 5). Moreover, a strong positive correlation was detected between cell and matrix PTHrP staining in early $\left(r_{s}=0.807, \mathrm{p}=0.028\right)$ but not in late AIA $\left(r_{s}=0.324, \mathrm{p}=0.395\right)$.

The relationship of PTHrP with cell density or with the Mankin score was further explored, and the most definite finding was a strong positive correlation between cell density and PTHrP positivity in surface cells $\left(r_{s}=0.631, \mathrm{p}=0.009\right)$. This was more evident in late AIA, where a decrease in surface cell density correlated with a PTHrP decrease in surface cells $\left(r_{s}=0.844, \mathrm{p}=0.004\right)$, and in surface matrix $\left(r_{s}=0.687, \mathrm{p}=0.041\right)$. The correlation between the Mankin score in late AIA and the PTHrP positivity in deep cells was poor $\left(r_{s}=0.473, \mathrm{p}=0.199\right)$.

\section{PTHrP detection in experimental OA}

Considering the whole OA cartilage samples together, these showed no significant differences in PTHrP immunostaining in either cartilage cells or matrix compared with the respective areas in controls. When PTHrP staining patterns in early (fig 1) and late OA (fig 2) cartilage samples were compared with those of controls, no significant differences were found in cells or matrix. Interestingly, distinct PTHrP positive cells were detected in proliferating clones at a late OA stage, but their small number was probably insufficient to raise the PTHrP semiquantitative score over that of controls. A strong correlation was found between cell and matrix staining for PTHrP in early OA $\left(r_{\mathrm{s}}=0.978, \mathrm{p}=0.004\right)$, but not in late OA $\left(r_{\mathrm{s}}=0.624, \mathrm{p}=0.376\right)$.

In OA samples the correlation of PTHrP staining in cells and matrix with the Mankin score was poor. More interesting was the correlation of PTHrP and cell density, where a strong correlation was found between surface cell density and PTHrP surface cell positivity $\left(r_{\mathrm{s}}=0.819, \mathrm{p}=0.007\right)$. Strikingly, cell density in the mid-zone also showed a significant correlation with PTHrP cartilage staining in surface cells $\left(r_{\mathrm{s}}=0.745, \mathrm{p}=0.021\right)$ and surface matrix $\left(r_{\mathrm{s}}=0.697, \mathrm{p}=0.037\right)$.

\section{Comparison of PTHrP staining pattern between AIA and OA models}

When PTHrP cell staining scores were compared in OA and AIA cartilage, PTHrP positivity was higher in OA samples in the mid-zone $(p=0.032)$. PTHrP matrix staining was also higher in OA cartilage, mostly in middle and deep regions ( $p=0.005$ and $p=0.008$, respectively) (fig 7).

Comparing both diseased cartilage models at an early stage (fig 1), cell density was higher in AIA $(p=0.048)$, while PTHrP positivity was significantly higher in the deep matrix of the OA group $(p=0.048)$. Dramatic changes in PTHrP

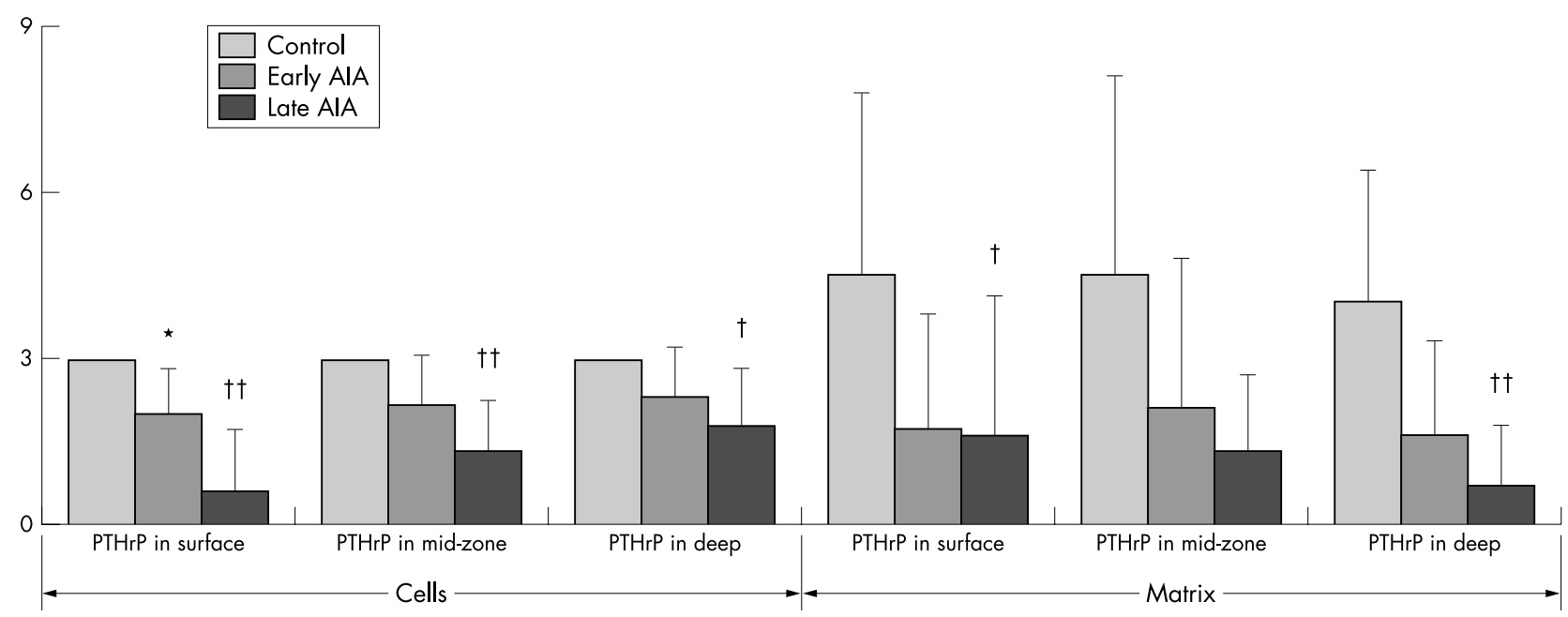

Figure 5 Crude score values (mean (SD)) for cartilage PTHrP staining in sequential AIA. Comparison with Mann-Whitney test between early AIA and controls ( $\left.{ }^{*} \mathrm{p}<0.05\right)$ and between late AIA and controls $(t p<0.05 ; \dagger \uparrow p<0.01)$. 


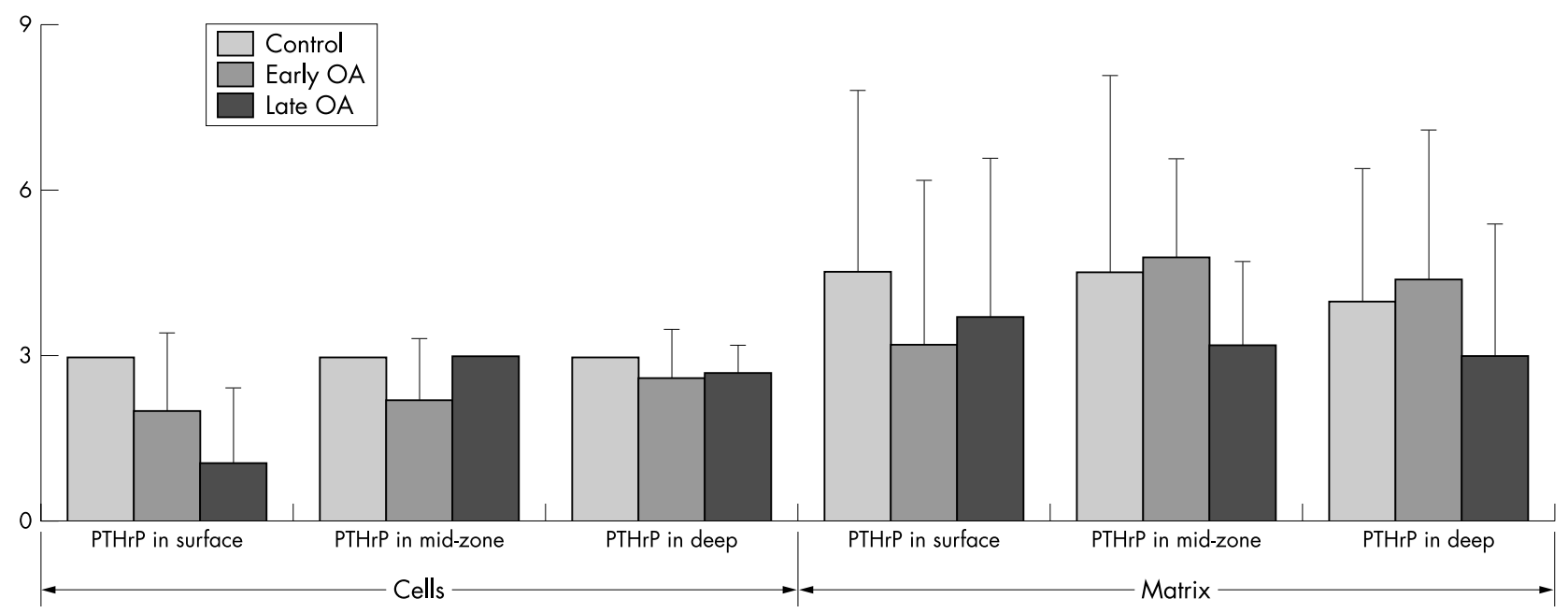

Figure 6 Crude score values (mean (SD)) for cartilage PTHrP staining in sequential OA. Comparison with Mann-Whitney test between early OA and controls, and between late OA and controls. Note that no significant differences were found in the crude variables.

staining were seen in these models with disease progression (fig 2). Samples of late OA cartilage at the mid-zone showed higher PTHrP cell positivity than corresponding AIA samples $(p=0.003)$. Interestingly, this was associated with the presence of proliferating clones in late OA cartilage (fig 3). PCNA staining showed an increased intensity in the surroundings of damaged cartilage areas, which further supported the presence of proliferating chondrocytes in these areas (fig 4). On the other hand, the cartilage surface showed no staining, while the mid- or deep regions without major damage exhibited only a moderate positivity (fig 4 ).

\section{DISCUSSION}

The role of PTHrP in the pathophysiology of joint diseases remains unclear. Immunoreactive PTHrP levels in synovial fluid are higher in patients with RA than in those with OA, suggesting that synovial PTHrP levels may reflect the disease activity, but its true effect on the diseased articular cartilage is unknown. ${ }^{20-22}$ When immunohistochemical staining and in situ hybridisation were used, PTHrP was detected in diseased cartilage chondrocytes, both in RA and OA, suggesting that it has a role in these pathological conditions. ${ }^{11}{ }^{13}$ In our study, cartilage PTHrP was immunolocalised in two well established rabbit models of inflammatory and degenerative arthritis. ${ }^{14-16}$ We used an experimental design which included a comparable joint biology before the arthritic injury that cannot be ensured in samples from human patients; and serial sectioning of the whole specimen to select truly damaged cartilage areas, and to avoid a selection bias in specimen collection, which may occur in a patchy cartilage disease such as OA.

Our results show a different PTHrP staining pattern during progression of both inflammatory and degenerative cartilage diseases. A decrease in cell and matrix PTHrP positivity was found in late AIA, consistent with previous findings in human cartilage specimens from patients with RA. ${ }^{13}$ Moreover, late AIA cartilage showed a prominent decrease of PTHrP positive cells (fig 5). This accompanied an increase in cell death, suggested by the observed decrease in cell density. Residual PTHrP staining remained in the matrix, surrounding chondrocytes and empty lacunae (fig 2). In OA cartilage, PTHrP positivity was similar to that in age matched controls. This is in contrast with two previous human studies, in which OA cartilage specimens, obtained at total joint replacement surgery, contained higher PTHrP than normal samples. ${ }^{11}{ }^{13}$ In one of these studies, ${ }^{13}$ however, moderately

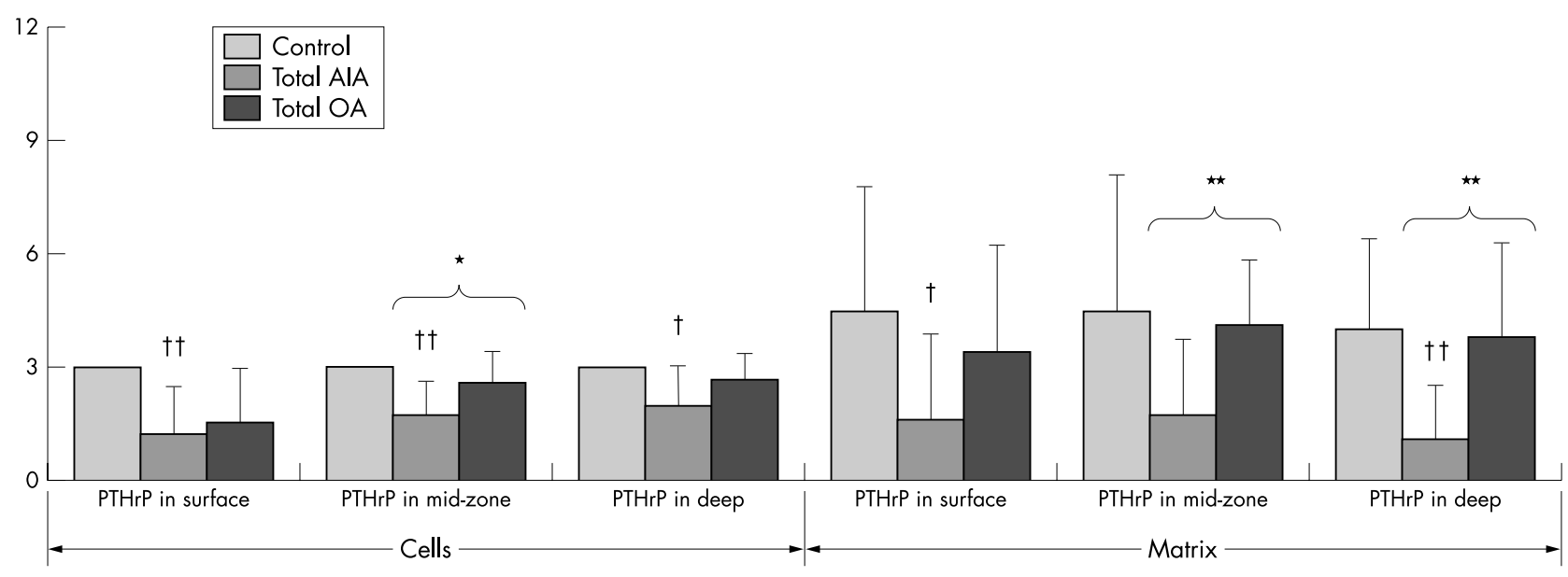

Figure 7 Crude score values (mean (SD)) for cartilage PTHrP staining in AIA and OA compared with controls. Comparison with Mann-Whitney test between AIA cartilage and controls ( $t p<0.05 ; \dagger \uparrow p<0.01$ ), and between OA cartilage and controls (not significant). Comparisons between AIA and OA cartilage samples are also displayed (* $\left.p<0.05 ;{ }^{* *} p<0.01\right)$. 
degenerated cartilage was found to contain higher PTHrP positive chondrocytes than the severely diseased tissue. Therefore, differences between these studies and the present study might be explained by difficulties in obtaining homogeneous samples in a patchy disease such as human $\mathrm{OA}$, or by a different severity in cartilage degeneration.

In late OA, PTHrP positivity was strikingly associated with the perilesional proliferating cell clones, as assessed by PCNA staining (fig 6). The difference between OA and AIA was clear in mid- and deep cartilage zones (fig 7). Interestingly, at a late AIA stage, PTHrP immunostaining was only maintained in preserved chondrocytes, and also in the matrix around some of these cells (fig 2). The repair mechanism(s) in OA cartilage seemed to be related to a stepwise increase in chondrocyte proliferating clones (figs 3 and 4). Thus, PTHrP, as inhibitor of chondrocyte maturation, ${ }^{23}$ might positively repair the damaged cartilage by modulating chondrocyte proliferation.

In summary, the observed changes in PTHrP staining and cell proliferation are different in inflammatory arthritis and degenerative post-meniscectomy OA models. In AIA, PTHrP decreases in parallel with the loss of chondrocytes. In contrast, OA samples, with a more advanced cartilage disease, show unchanged PTHrP patterns, although proliferating chondrocyte clones display increased PTHrP staining. The latter might probably occurs as an attempt towards cartilage regeneration. These findings provide further insights into the pathogenic role of PTHrP in the diseased cartilage.

\section{ACKNOWLEDGEMENTS}

We thank Juan J Granizo, MD, Epidemiology Unit, Fundación Jiménez Díaz, for statistical analysis; and Professor Y Konttinen, MD, $\mathrm{PhD}$, for critical revision of the manuscript.

This study is supported in part by grants from Instituto de Salud Carlos III (FIS 00/0125 and C03/08).

\section{Authors' affiliations}

E Gomez-Barrena, Bone and Joint Research Laboratory, Fundación Jiménez Díaz, and Department of Surgery, Universidad Autónoma, Madrid, Spain

O Sánchez-Pernaute, R Largo, E Calvo, Bone and Joint Research Laboratory, Fundación Jiménez Díaz, Madrid, Spain

P Esbrit, Bone and Mineral Research Laboratory, Fundación Jiménez Díaz, Madrid, Spain

G Herrero-Beaumont, Bone and Joint Research Laboratory, Fundación Jiménez Díaz, and Department of Medicine, Universidad Autónoma, Madrid, Spain

\section{REFERENCES}

1 Philbrick WM, Wysolmerski JJ, Galbraith S, Holt E, Orloff JJ, Yang KH, et al. Defining the roles of parathyroid hormone-related protein in normal physiology. Physiol Rev 1996;76:127-37.

2 Strewler GJ. The physiology of parathyroid hormone-related protein. N Engl J Med 2000;342:177-85.

3 Zerega B, Cermelli S, Bianco P, Cancedda R, Cancedda FD. Parathyroid hormone [PTH(1-34)] and parathyroid hormone-related protein [PTHrP(1-34)] promote reversion of hypertrophic chondrocytes to a prehypertrophic proliferating phenotype and prevent terminal differentiation of osteoblast-like cells. J Bone Miner Res 1999;14:1281-9.

4 Karaplis AC, Luz A, Glowacki J, Bronson RT, Tybulewicz VL, Kronenberg HM, et al. Lethal skeletal dysplasia from targeted disruption of the parathyroid hormone-related peptide gene. Genes Dev 1994;8:277-89.

5 Van der Kraan PM, Bakker AAAD, Vitters EL, Van den Berg WB. Culture of bovine articular cartilage in the presence of a PTHrP antagonist leads lo increased collagen type X mRNA expression. Trans Orthop Res Soc 1999;24:732

6 Vortkamp A, Lee K, Lanske B, Segre GV, Kronenberg HM, Tabin CJ. Regulation of rate of cartilage differentiation by Indian hedgehog and PTHrelated protein. Science 1996;273:613-22.

7 Lanske B, Divieti P, Kovacs CS, Pirro A, Landis WJ, Krane SM. The parathyroid hormone (PTH)/PTH-related peptide receptor mediates actions of both ligands in murine bone. Endocrinology 1998;139:5194-204.

8 Mannstadt M, Jüppner H, Gardella TJ. Receptors for PTH and PTHrP: their biological importance and functional properties. Am J Physiol 1999:277:665-75.

9 Amizuka N, Henderson JE, White JH, Karaplis AC, Golztman D, Sasaki T, et al. Recent studies on the biological action of parathyroid hormone (PTH)related peptide (PTHrP) and PTH/PTHrP receptor in cartilage and bone. Histol Histopathol 2000;15:957-70.

10 Funk JL. A role for PTHrP in the pathogenesis of inflammatory/autoimmune diseases. Int Immunopharmacol 2001;1:1101-21.

11 Terkeltaub R, Lotz M, Johnson K, Deng D, Hashimoto S, Goldring MB, et al. Parathyroid hormone-related protein is abundant in osteoarthritic cartilage, and the parathyroid hormone-related protein 1-173 isoform is selectively induced by transforming growth factor beta in articular chondrocytes and suppresses generation of extracellular inorganic pyrophosphate. Arthritis Rheum 1998:41:2152-64.

12 Karpouzas GA, Terkeltaub RA. New developments in the pathogenesis of articular cartilage calcification. Curr Rheumatol Rep 1999;1:121-7.

13 Okano K, Tsukazaki T, Ohtsuru A, Osaki M, Yonekura A, Iwasaki K, et al. Expression of parathyroid hormone-related peptide in human osteoarthritis. J Orthop Res 1997; 15:175-80.

14 Sánchez-Pernaute O, López-Armada JM, Hernández P, Palacios I, Navarro F, Martínez J, et al. Antifibroproliferative effect of tenidap in chronic antigeninduced arthritis. Arthritis Rheum 1997;40:2147-56.

15 Benito MJ, Sánchez O, López MJ, Hernández P, Palacios I, Egido J, et al. Cyclosporin A prevents the histologic damage of antigen arthritis without induction of fibrosis. Arthritis Rheum 2000;43:311-19.

16 Calvo E, Palacios I, Delgado E, Sánchez O, Hernández P, Ruiz-Cabello J, et al. High resolution MRI shows that increased cartilage thickness precedes subchondral remodeling in experimental osteoarthritis. Osteoarthritis Cartilage 2001;9:463-72.

17 Van der Sluijs JA, Geesink RGT, Van der Linden AJ, Bulstra SK, Kuyer R, Drukker J. The reliability of the Mankin score for osteoarthritis. J Orthop Res 1992;10:58-61.

18 Largo R, Gomez-Garre D, Santos S, Penaranda C, Blanco J, Esbrit P, et al Renal expression of parathyroid hormone-related protein (PTHrP) and PTH/ $\mathrm{PTH} \mathrm{PP}$ receptor in a rat model of tubulointerstitial damage. Kidney Int 1999;55:82-90.

19 Valín A, García-Ocaña A, de Miguel F, Sarasa JL, Esbrit P. Antiproliferative effect of the $\mathrm{C}$-terminal fragments of parathyroid hormone-related protein, PTHrP-(107-111) and (107-139), on osteoblastic osteosarcoma cells. J Cell Physiol 1997; 170:209-15.

20 Okano K, Tsukazaki T, Ohtsuru A, Namba H, Osaki M, Yonekura A, et al. Parathyroid hormone-related peptide in synovial fluid and disease activity of rheumatoid arthritis. Br J Rheumatol 1996;35:1056-62.

21 Kohno H, Shigeno C, Kasai R, Akiyama H, lida H, Tsuboyama T, et al. Synovial fluids from patients with osteoarthritis and rheumatoid arthritis contain high levels of parathyroid hormone-related peptide. J Bone Miner Res 1997; 12:847-54.

22 Yoshida T, Horiuchi T, Sakamoto H, Inove H, Takayanagi $H$, Nishikawa T, et al. Production of parathyroid hormone-related peptide by synovial fibroblasts in human osteoarthritis. FEBS Lett 1998:433:331-4.

23 Iwamoto M, Kitagaki J, Tamamura Y, Gentili C, Koyama E, Enomoto H, et al. Runx2 expression and action in chondrocytes are regulated by retinoid signaling and PTHrP. Osteoarthritis Cartilage 2003;11:6-15. 